\title{
Research on Development of Physical Fitness in Physical Education Teaching
}

\author{
Yili Sun*
}

Department of Physical Education, Hebei University of Science And Technology, Shijiazhuang, 050018, Hebei, China

\begin{abstract}
The physical fitness quality is the basis of the students' comprehensive quality, and it is the essential condition of the development of individual growth. But today's school is more emphasis on the students' learning culture results instead of physical education. With the growth of the level of life, physical quality has declined. This paper expatiates the reason of contemporary students' physical fitness and physical quality decline, and it's focus on studying and discussing the cultivation of physical ability in the teaching of physical education is an important part of quality education, and provides strategies to improve physical fitness from the perspective of teachers and students. Finally the conclusion is drawn: each student's physical quality training in physical education teaching is different, the development of physical quality not only improves student's the physical fitness, but also conducives to the psychological development of the students. Physical education teaching should pay more attention to the training of physical quality in the future.
\end{abstract}

Keywords: Comprehensive quality, physical education, physical fitness quality, psychological.

\section{INTRODUCTION}

Physical Education is one of the important areas of school education to cultivate morality, intelligence, body beauty and harmonious development, so it is indispensable to students' physical education and their physical fitness training. Generally speaking, physical education just attach importance to theory rather than the application, and even some schools just through some single, one-sided achievement assessment methods to determine the physical ability of the students, these methods cannot truly achieve the goal of training and education, and what's more, it also cannot satisfy the students working in the future energy demand [1]. The physical education should enhance students' physical training and fundamentally solve the dilemma of current PE teaching system to help students facing the demand for jobs after graduation etc. How to develop students' physical ability and meet the needs of school education development, is our general physical education teacher's concerned problem. Physical fitness is an important part of the constitution, the development of students' physical fitness is one of the important goals of school physical education, and it is the school sports distinction between the signs of education activities [2]. The development of students' physical fitness not only plays an important role in improving students' sports skills, but also can strengthen students' physique and improve students' physical and mental health.

Physical fitness refers to the physical and anatomical characteristics of the students' individual and the physical ability of the students to learn and practice. Physical quality is the material premise of other quality cultivation, directly or indirectly affect the formation and development of students' other quality. Contemporary college students have the responsibility to enhance the comprehensive national strength and the revitalization, as a result, the physical quality of the students in relation to the national prosperity and national prosperity. With the rapid development of social economy in China, the material life of the people has been greatly improved, while the physical quality of the students has declined [3]. As an important part of quality education, physical education needs to adhere to the principle of peopleoriented and sustainable development, and to cultivate students' physical quality and lifelong sports ability.

\section{THE CURRENT SITUATION OF STUDENTS' PHYSICAL QUALITY AND PHYSICAL EDUCATION}

\subsection{The Current Situation of Students' Physical Quality}

In 2002, the "National students' physical health monitoring network" carry out a monitoring of physical fitness quality in every two years. The object of the monitoring was in the age from 7 to 22 , and the number of the students was 182964. The monitoring results showed that the students of lower limb explosive force of standing long jump, compared the level with 2002, in addition to the slight increase the level of male college students, other age groups showed downward trend. Compared with the result in 2002, it reflect the body flexibility level of the age group had a $60 \%$ decline. The vital capacity level except the high school above (22 16 years old) boy's vital capacity level to have the increase, the rest all assumes the tendency.

\subsection{The Current Situation of Physical Education}

\subsubsection{The Teaching Objective is Not Clear Enough}

The purpose of physical education in school is to promote students' physical and mental health, so that students 
can master the knowledge of life exercise and cultivate their sentiment [4]. But the majority of our physical education has been stuck in the level of physical and athletic standards compliance, single teaching objectives and the teaching purpose is not clear enough, just individually completed the teaching content, but ignore the students' mental health, and it makes students produce weariness and also ignore whether students master the teaching content, it means that "formalism" was appeared in physical education.

\subsubsection{Physical Education Cannot Suit Student's Measures to Local Conditions and Teach Students in Accordance with their Aptitude}

Nowadays, the physical education mostly takes the unified standard of the whole country and neglect the different characteristic of different places [5]. Mountain area of school physical education and urban areas of sports teaching will inevitably have different content, but most of the school physical education ignored this difference and still in accordance with national standards for teaching, which means that it really corny and boring, and most of the students tend to have no interest in it.

\subsubsection{Teachers Don't Pay Enough Attention to Physical Education}

Some teachers in the classroom indulge students and make the physical education turns to some "sheep" [6] teaching. So the students considered that physical education is not a formal course, so many students don't value the course and they become more and more lazy [7]. Because there is no real teacher arrangement of the teaching content and the lack of physical exercise, as a result, it makes the body quality sharp drop a lot.

\section{THE REASONS FOR THE DECLINE OF COLLEGE STUDENTS' PHYSICAL QUALITY}

The school is not attached to physical education, at the same time, the sports related regulations are not perfect. The physical education has not been attached importance, especially in the initial stage, in order to improve the entrance rate [8], the students' sports activity time is far from enough, the physical quality has the tendency to fall (see Fig. 1). Because the sports teacher to the relevant regulations and system are not so familiar, it leads to some sports difficult to carry out smoothly.

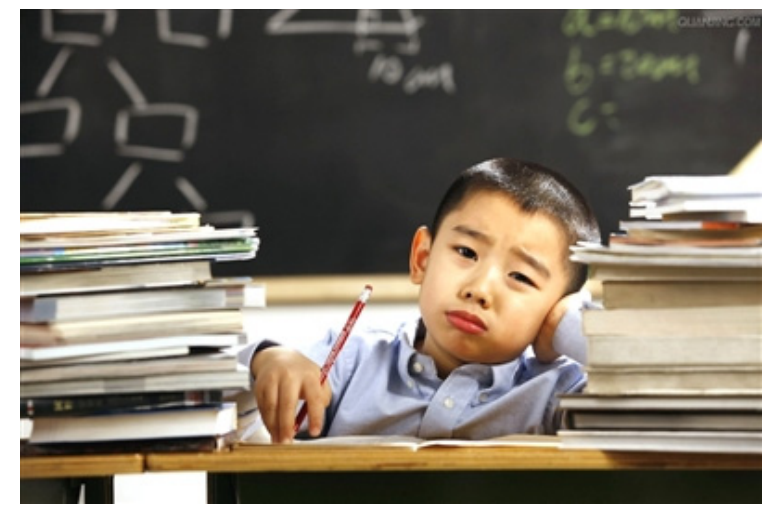

Fig. (1). Massive of homework leads student's lacking time to participate in sport.
The students' participation and the consciousness of sports are not strong, and the value of physical education is not enough. College Students' physical exercise participation is not high, generally speaking, boys in physical exercise participation attitude is better than girls, although it is well known that physical exercise is an effective method to enhance the health, but the awareness of physical exercise for the development is still far from enough, even if part of the university students have physical exercise consciousness, but to participate in physical exercise for different purpose, only a few students exercise is clear to enhance the physical objective. Coupled with the college students after school life rich and colorful, there is no pressure on the entrance, there is more time to do other leisure activities and the time of extra-curricular exercise has been reduced.

Sports optional teaching mode is single [9], which leads students to escape from the physical education program. The sports option teaching pattern paid too much attention to the single item skill learning, most of the content of sports elective courses in Colleges and universities is basically dominated by the technical teaching of sports, and once the students selected a project, no matter the project to improve the physical quality has no significant effect, the students should learn it in a semester or academic year. However, most students choose the easy one, which means that it will easy to pass the exam, to escape the physical class project to learn. As a result, the students in the physical education is not exercise, of course, it is also difficult to improve the physical quality.

The students lack the knowledge of extracurricular physical exercise and always lack of regular and effective exercise. Because of the improvement of living conditions, the reduction of physical labor and the emphasis on the development of intelligence, the students lack the necessary sports and the phenomenon of the students' physical fitness is generally decreased. In comparison, after school sports activities have some advantage in the time and the organization form, it has a greater flexibility and pertinence, more suitable for students' individual needs. The majority of college students' physical exercise are lack of scientific understanding, but most of them would like to accept the teacher's guidance and the demand on the knowledge of physical exercise, which is to university extracurricular sports activities of the organization to carry out.

The sports related facilities in school cannot meet the needs of physical exercise for college students (see Fig. 2). Because of the increase in enrollment and the number of students, the related facilities of university sports are serious shortage [10]. Many colleges and universities for the construction of the stadium, the lack of hardware facilities, as a result, it has a serious impact on the development of college students' extracurricular exercise, which leads to the decline of college students' physical fitness.

\section{THE IMPORTANCE OF PHYSICAL TRAINING IN PHYSICAL EDUCATION}

\subsection{Physical Training is an Important Way to Cultivate Students' Emotion and Will Quality}

Students' main psychological characteristics of personality is relatively strong, ideological change quickly and most 


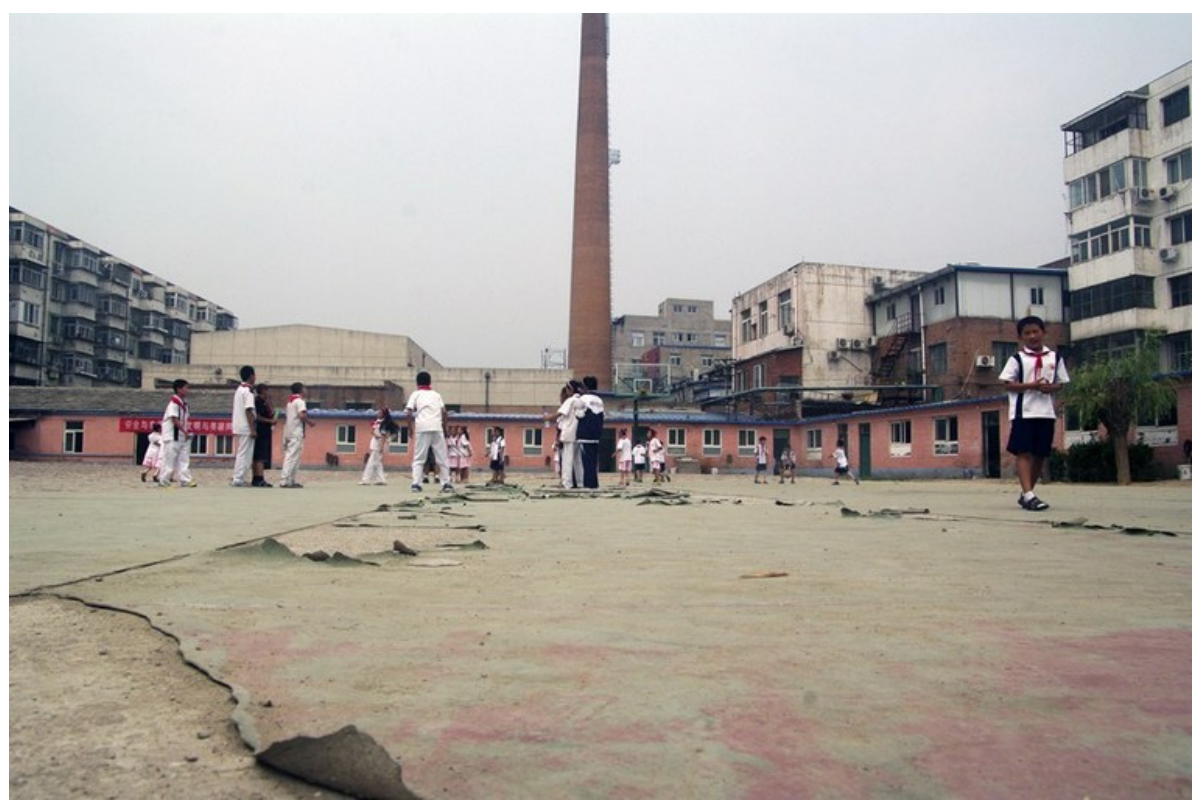

Fig. (2). The shabby athletic facilities.

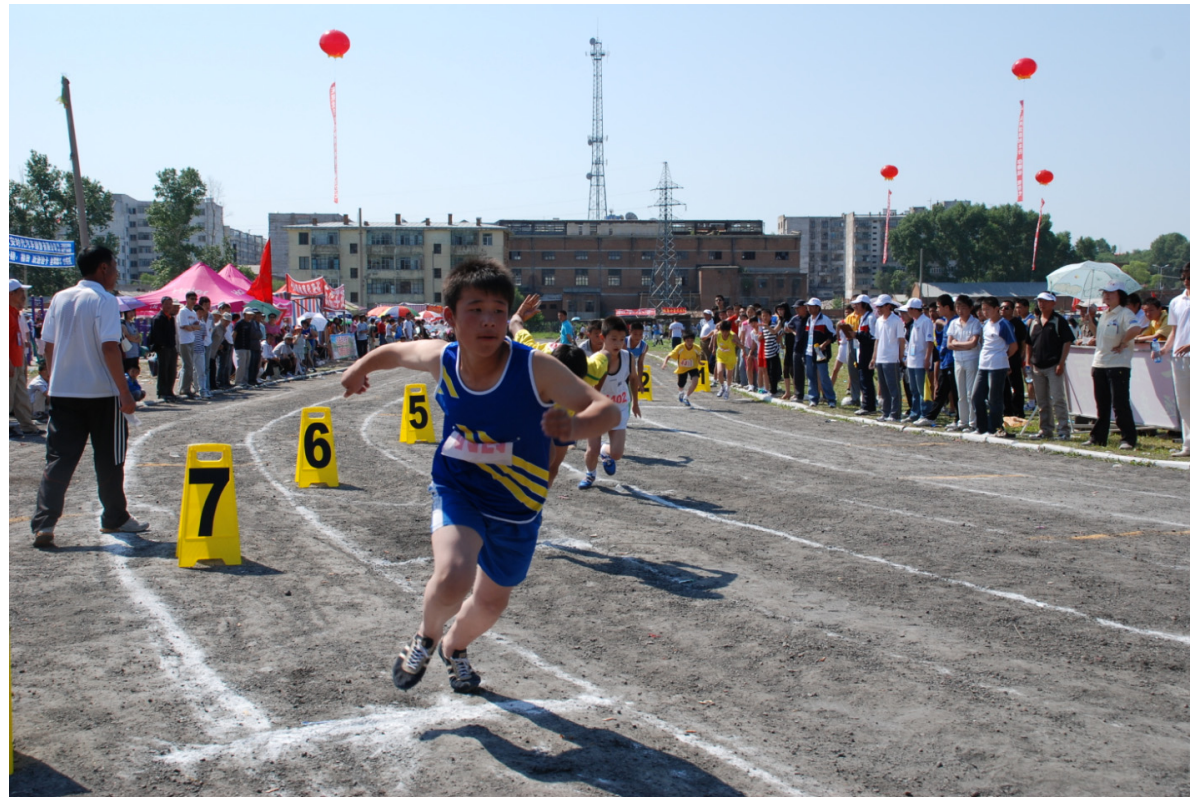

Fig. (3). Students take active part in sports activities.

of the students due to the influence of the factors such as society and family, mental deformity, treat things twisted idea is particularly serious, more psychologically vulnerable while playing heart is also very important. These are school teachers should understand and master, so in physical education we should try to change the students' Outlook on life, values, through various methods. At the same time in the daily physical education student's emotion also can manifest the characteristic strongly, richly colorful, the tense variable, the enthusiasm or the negativity and so on [11] (see Fig. 3). The creation and the change of mood affect the ability of the body to the body directly and show it in the form of sports performance. A strong sense of satisfaction, relaxed motivation can stimulate the participation in sports activities. Have confidence, high emotional, courageous, tenacious positive emotions, can get good results. So in the physical education, it should use many kinds of methods to encourage and encourage students, and give them confidence, but also can improve students' physical quality, improve students' physical ability. In addition, the willpower is consciously control their own actions and overcome subjective and objective difficulties, the inhibition of emotional impulse, to avoid the occurrence of adverse action, focus, so as to better achieve the goal of complex process. Quality of willpower is calm and decisive, tenacious perseverance, persistence.

\subsection{Physical Training has Positive Effect on the Cultiva- tion of Students' Personality Traits}

The personality has both the common features of the psychological activities and the psychological features of the individual. Good personality style can form a huge spiritual 
strength. Physical training is achieved through the training of technology and sports competition. It has a special effect on the development and formation of personality. So all the sports training as an important means of cultivating personality. Teachers should observe, analyze and understand the physical quality, psychological characteristics and personality differences of students through physical training. Objective to arrange different activity items, organize different physical training, and bring forward different requirements, develop and mold the good personality of the students in different stages.

\subsection{The Special Significance of Physical Training to De- velop Students' Intelligence}

The training of physical ability needs the physiological and psychological factors of the aspects of the training. In the training process, enhance the function of nervous system, increase the intensity of the cerebral cortex neural activity in the process, balance, flexibility, adaptability, intelligence development of students have important significance.

\subsection{Physical Training is an Effective Channel for Stu- dents to Carry out Moral Education}

Moral education need theory and social practice, so that moral understanding in the moral emotion inspired to develop a good moral behavior habits. Therefore, consciously using the stamina and the emotional attitude of the physical training methods to make the students self-moral education, but also an important channel for the cultivation of good qualities and an effective way. Especially in sports in our country is booming, the 2008 Olympic Games, the World Games successfully held, etc., are generally concerned by the majority of young people, through the visit of sports competitions, the young students of collectivism, patriotism and moral quality of education, there will be more and more important significance.

\section{THE CULTIVATION TACTICS OF PHYSICAL ABILITY IN PHYSICAL EDUCATION}

Universities should strengthen the school sports, improve the awareness of the importance of physical education. First, we should conscientiously implement the college sports related policies, and overcome the thought of intellectual light sport, sports school upgraded to a great height. Secondly, to strengthen the supervision and supervision to the work of physical education in Colleges and universities, and ensure the college students' physical training venues and exercise, and comprehensively promote the development of College Students' physical fitness. Again, the management department of colleges and universities should conform to physical education reform trend, seize the opportunity and innovation, and strengthen the management of physical education, the progressive realization of the scientific and systematic management of PE courses.

To reform the teaching mode, open basic physical education. First, under the influence of the reform of physical education in Colleges and universities, forming a phenomenon of the coexistence of a variety of teaching mode, for example say the school elective course teaching mode, in Shenzhen University to represent the club teaching mode, to Tsinghua
University on behalf of the "three self" teaching mode, South Polytechnic as the representative of the integration of classroom teaching mode and so on. The combination of various teaching mode is of benefit to improve students' interest, satisfy students' personality development and cultivate students' habit of lifelong exercise. Secondly, in the course of setting up optional courses, pay attention to the development of basic physical education. The exercise of basic physical ability is beneficial to the coordination development of the function of the organism of the students, so it has the complete exercise ability. Through the basic physical and school teaching, both can strengthen the students' physical ability, and can develop the students' personality and specialty. Again, to build a scientific student physical development evaluation system. In the evaluation of College Students' physical fitness, it is necessary to consider the individual difference of the students' level of physiological function, physical quality and psychological quality, with the combination of self-evaluation and evaluation of teachers, stage of evaluation and tracking evaluation method to on students' physical condition were comprehensive, objective and accurate evaluation.

Physical education teachers should understand the essence of core area training idea, functional training idea and balanced development concept, so as to make them apply to teaching practice.. These training ideas mainly pay attention to the exercise of the nervous and control ability of individual exercise, and to improve the coordination, balance and stability of the multi muscle groups during the exercise. Therefore, in the course of teaching, the first need to pay attention to guide students to apply the new strength training method, multi way to solve the problem of neural control of power. Second pay attention to let the students set up the action is the concept of technology. The action bearing movement quality and technology, the action pattern decides the movement performance, the perfect motion technology can strengthen and make up for "physical ability". Third, we must pay attention to the balanced development of students' physical structure (such as core and limbs, local and overall, on the left and on the right side of), function (such as heart and lung function and endurance, sensitive quality and speed, quality, strength, quality and flexibility). The system structure determines the function of the system, structure of balanced development affects equilibrium function, modern physical training more emphasis on action stability, symmetry and complete kinetic chain, physical education teachers in the teaching process of these ideas to permeate.

The combination of extracurricular sports activities, strengthen the construction of school sports clubs. First, colleges and universities to carry out the extracurricular sports activities, on the project should as far as possible to meet the students' needs and interests, vigorously carry out those facilities on the request is not high, the students are very interested in sports and activities shall strive to enrich, pay attention to development of College Students' physical quality and cultivate a lifelong sports consciousness and ability. Many colleges and universities in the active club form the extracurricular activity, lets the more student participate in the physical exercise to go to (see Fig. 4). Secondly, strengthen the organization and management of the sports club, set up a sound sports club, organizational structure, the 


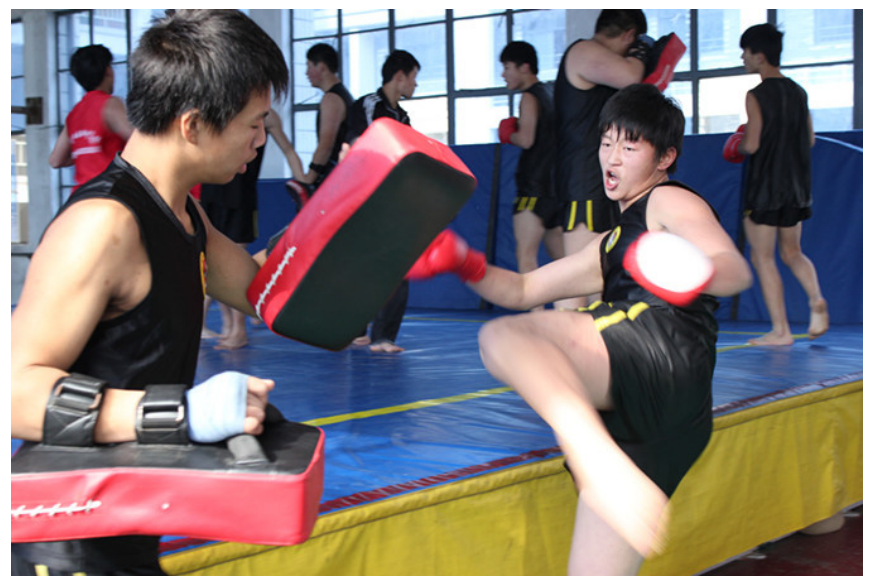

Fig. (4). Sports clubs arouse students' interest easily.

combination of inside and outside class sports club management, for students to create a relaxed, pleasant atmosphere of fitness and the environment. Again, it is necessary to improve the management system of university physical fitness test, teachers should recognize the importance of physical fitness test, classroom teaching should pay attention to the all-round development of the students' physical quality, can also be the student physical standard into the workload of teachers, the enthusiasm of the teachers' work motivation.

Increase the investment of university sports funds, improve the construction of sports related facilities. First of all, the college sports departments should arrange and reasonably use the existing sports venues and facilities, as far as possible to provide students with some activities, but also to open up more free space. Secondly, to change the concept, increase the investment and reasonable planning of sports funds, strengthen the comprehensive exploitation and utilization of school sports facilities and resources. Again, to the students free and open school sports facilities, while the sports teachers should strengthen the supervision and guidance of after-school physical exercise.

\section{CONCLUSION}

School students have outstanding personality and each student has different personality, we should according to actual circumstances, at the same time, every one of the students also have in common, so there should be plans to potential culture and mining. Physical training in the teaching of physical education not only promote the harmonious development of body and mind, mastery of traditional health care knowledge and skills, it also focus on the highlighting role of students, stimulate students' interest in sports and hobbies, play individual strengths and potential, reflected in the course of physical education teaching flexibility and initiative. Training of physical ability can adapt to the future social development and it can lay the foundation for lifelong physical education, the form of financial theory, skills, quality and fitness for various sports teaching and examination system. It is very necessary to improve the physical fitness of students, which can not only improve students' physical quality, enhance students' physical fitness, for employment play good physical basis, more in Ideological Education on students adjust life view, value view, pave the way for the students of the future path in life a good thought, which fully embodies the importance of school physical education in physical training.

\section{CONFLICT OF INTEREST}

The author confirms that this article content has no conflict of interest.

\section{ACKNOWLEDGEMENTS}

Declared none.

\section{REFERENCES}

[1] C. B. Khaokham, S. Hillidge, and S. Serpas, "Comparison of height, weight, and body mass index data from state - mandated school physical fitness testing and a districtwide surveillance project," Journal of School Health, vol. 85, no. 5, pp. 327-333, 2015.

[2] F. Trudeau, L. Laurencelle, and C. Lajoie, "Energy expenditure at work in physical education teachers," Applied ergonomics, vol. 46, pp. $218-223,2015$.

[3] L. Goossens, G. Cardon, and E. Witvrouw, "A multifactorial injury prevention intervention reduces injury incidence in Physical Education Teacher Education students,"European journal of sport science, vol. 21, no. 2, pp. 1-12, 2015.

[4] D Kahan, and T. L. McKenzie, "The potential and reality of physical education in controlling overweight and obesity," American Journal of Public Health," vol. 105, no. 4, pp. 653-659, 2015.

[5] K.. Oliver, H. A. Oesterreich, and R. Aranda, 'The sweetness of struggle': innovation in physical education teacher education through student-centered inquiry as curriculum in a physical education methods course," Physical Education and Sport Pedagogy, vol. 20, no. 1, pp. 97-115, 2015.

[6] D. A. Dudley, P. Pearson, and A. D. Okely, "Recommendations for policy and practice of physical education in culturally and linguistically diverse Australian secondary schools based on a two-year prospective cohort study," School Psychology International, vol. 36 , no. 2, pp. 172-188, 2015

[7] S. Srikanth, T. A. Petrie, and C. Greenleaf, "The relationship of physical fitness, self-beliefs, and social support to the academic performance of middle school boys and girls," The Journal of Early Adolescence, vol. 35, no. 3, pp. 353-377, 2015.

[8] R. Ferriz, D. González - Cutre, and Á. Sicilia, "Predicting healthy and unhealthy behaviors through physical education: A self - determination theory - based longitudinal approach,"Scandinavian Journal of Medicine \& Science in Sports, vol. 20, no. 2, pp. 44-50, 2015.

[9] A. Wrench, and R. Garrett, "Gender encounters: becoming teachers of physical education," Sport, Education and Society, vol. 2, pp. 1$17,2015$.

[10] B. C. Chow, T. L. McKenzie, and L. Louie, "Children's physical activity and associated variables during preschool physical education," Advances in Physical Education, vol. 5, no. 1, p. 39, 2015.

[11] K. Walseth, "Muslim girls' experiences in physical education in Norway: What role does religiosity play?," Sport, Education and Society, vol. 20, no. 3, pp. 304-322, 2015. 